\title{
Individual based simulation for online marketplace diffusion among trading small medium enterprises: A conceptual framework
}

\author{
Singgih Saptadi ${ }^{1,2, *}$, Arlita Rahma Widyasrini ${ }^{1}$, Bonita Melinda Pangaribuan ${ }^{1}$, Sriyanto ${ }^{1}$ \\ and Ary Arvianto ${ }^{1,2}$ \\ ${ }^{1}$ Industrial Engineering Department, Diponegoro University, Semarang, Central Java, Indonesia \\ ${ }^{2}$ Logistics and E-Business Research Center, Diponegoro University, Semarang, Central Java, \\ Indonesia
}

\begin{abstract}
The number of Indonesian SMEs and Indonesian Internet users are increasing. This situation is of concern to the Indonesian government. The government then launched a SME go online program with a target of 8 million SMEs using the online platform in 2019. One of the online platforms that SMEs may use in Indonesia is the online marketplace such as Tokopedia, Bukalapak and others. Previous research studied the factors that support or hinder the adoption of e-commerce in SMEs environment but had not explored how the interaction of those factors in the adoption of online marketplace. In a social system, the diffusion and adoption of online marketplaces in SMEs is influenced by socio-economic characteristics, personality variables and communication behaviours that exist and are acquired by individuals. This paper describes a conceptual framework for the development of an individual-based simulation commonly referred to as an agent-based simulation to understand the adoption by SMEs and the diffusion of online marketplace in SME environments.
\end{abstract}

\section{Introduction}

Small and medium enterprise (SME) is a labor-intensive company with requirements such as education, worker skills, capital or technology tend to be simple [1]. Indonesian Ministry of Cooperatives and Small Medium Enteprises stated that the number of SMEs in Indonesia in 2013 amounted to $57,800,000$ units $(99.9 \%$ of business enterprises in Indonesia). With that amount, SMEs have huge contributions to Indonesian economy within last five years that are $60.34 \%$ of Product Domestic Brutto and $97.22 \%$ of national employment (http://www.kemenperin.go.id/artikel/14200/Kontribusi-UMKM-Naik).

Internet has a very rapid user growth. Currently, internet penetration in Indonesia reached $53.7 \%$ of population [2] and this means more than 140 million internet users in Indonesia. With a huge and growing market potential, internet use by SMEs is a concern of Indonesian government. Considering the contribution of SMEs to Indonesian economy and the economic potential of the internet, the government launched a SMEs go online program

\footnotetext{
*Corresponding author: singgihs@ft.undip.ac.id
} 
with a target of 8 million SMEs utilizing online platforms in 2019 [3]. An online platform that is feasible to be utilized by SMEs freely and easily is marketplce online in Indonesia. Some of the known online marketplace are Tokopedia, Bukalapak and others. Unfortunately, until 2017 only 3.79 million SMEs that utilize the online platform.

The online marketplace is a form of e-commerce that is often referred to as multichannel ecommerce. The development of internet technology enables the emergence of new varieties of e-commerce. As an innovation, the online marketplace is perceived as something new [4] in marketing SME products. The diffusion of online marketplace in the SMEs environment is influenced by various factors, both the supporting factors and the inhibiting factor of online marketplace adoption by SMEs..

Some researches studied the factors that support or hinder the adoption of e-commerce, especially in the SMEs. MacGregor \& Vrazalic studied factors that drive e-commerce adoption by SMEs in Wollongong (Australia) and Karlstad (Sweden) [5]. These factors are: consumer demand, increased sales, and increased control of goods. Govindaraju \& Chandra studied the inhibiting factor of e-commerce adoption by SMEs in Indonesia and showed that human resource and sources of information as two inhibiting factors [6]. Saptadi et al examined the influence of SME owners' support and SMEs IT sophistication on IT adoption by SMEs [7].

These studies have not explored how the interaction of various factors in the adoption of online marketplace. The diffusion of the online marketplace, as well as the diffusion of other innovations, occurs in a social system. In social systems, the diffusion of the online marketplace in SME environments and the adoption of online marketplace by an SME is influenced by social factors and individual characteristics of the adopters. Based on this, the study sees the need for an understanding of the adoption of online marketplaces by SMEs and the diffusion of online marketplaces among SMEs through a model that illustrates the individual characteristics of the adopter and of the social system. We therefore examine the development of an individual-based model commonly referred to as an agent-based model to understand the adoption by SMEs and the diffusion of online markeplace in SME environments.

This paper explains our initial idea of individual-based modeling for online marketplace diffusion. In the next section, we describe some concepts related to the diffusion of innovation in the social systems that mostly we adapt from Rogers [4]. Then, we explain the conceptual framework that we use as the basis for the next activity in this study. This paper concludes with an explanation of our next research agenda.

\section{Difusion of Innovation and Individual Based Modeling}

Diffusion is a process of an idea or innovation communicated or dispersed through certain channels at a time period among members of its social system. Innovation is an idea or practice that is perceived new by individuals who will adopt it or apply it [4]. Messages or information disseminated in the process of interaction or communication containing ideas, ideas or practices that are considered new. According to Rogers, the diffusion of innovation is influenced by four elements: the innovation itself, communication channels, time, and social systems [4].

Researchers understood that individual decision about an innovation is not an intantaneous act. The adoption decision process of an innovation by a decision maker unit is an individual process where the adopter knew the innovation, got additional knowledges about the innovation and followed by accepting or rejecting the innovation [4]. Individual decision-making process for adopting an innovation are influenced by socio-economic characteristics, personality variables and communication behaviours of individuals. An innovation, like marketplace online, enters a social system which has a unique socio- 
economic structure. an online marketplace is also exposed to individuals who have diverse personalities and communicating behaviors [4]. Considering the online marketplace will be adopted by SMEs that have various characters and diffused in the social environment of SMEs, then understanding the diffusion of the online marketplace in SMEs requires methods that consider the characteristics of individuals that live within a social system.

Individual-based simulation is a form of computational modeling in which a phenomenon of the agent and its interactions is modeled. The modeled phenomena include the characteristics of agents, environments, and descriptions of interactions between agents and agents with their environment [8]. The answer is that in ecology, the individuals are not atoms but living organisms. Individual organisms have properties an atom does not have. Individuals grow and develop, changing in many ways over their life cycle. Individuals reproduce and die, typically persisting for much less time than the systems they belong to. Individuals need resources, so they modify their environment. Individuals differ from each other, even within the same species and age, so each interacts with its environment in unique ways [9].

\section{The Conceptual Framework}

In this section, we discuss the conceptual framework underlying this research. The first part of the conceptual framework is the definition of an agent. The agent or entity in this study is the decision maker in SMEs (we shortly name as SMEs), and the government. An SME interacts with other SMEs through conversations with other SMEs, news from mass media or facilitated training by the government.

As an agent, each SME has individual attributes, namely (1) adoption status as adopter or non-adopter, (2) the initial value of any inhibiting factors and drivers. In this study, we involve some of the following factors derived from previous studies: (a) Have educated human resources; (b) Knowledge of the benefits of online marketplaces; (c) Knowledge of implementation of online marketplaces; (d) Experience using electronic marketing media; (e) Have time to learn an online marketplace; (f) Have time to operate an online marketplace; (g) Online marketplace compliance with business processes; (h) Have support from management to use online marketplace; (i) the threat from competitors who are using online marketplace; (j) Get information about online marketplace from media; (k) Consumer order through online marketplace; (l) Sales increase; (m) Improved control and follow-up.

The value of these variables will change with the interaction of SMEs with other agents as well as news from the mass media. Based on the values of these attributes, SMEs may accept or reject the adoption of an online marketplace.

Process overview is the second part of this conceptual model. Process overview discusses the sequence of activities that agent will perform and when the individual attribute will be updated [10]. Fig. 1 illustrates the process overview of this model. First channel in diffusing marketplace online is agent-to-agent interaction. Initial simulation will initialize the state variable of each agent. The adopter agent as will be a partner on the interaction of the conversation. The non-adopter agents as potential adopter, if interacting with the adopter will get additional value each individual attribute (drivers or inhibiting fators of adoption). If the value of each of the driver and inhibiting factors of online marketplace adoption is greater than the average adopter value of each factor, then agents with potential status will be satisfied with their interactions and then they may become new adopter or stay as non-adopter. 


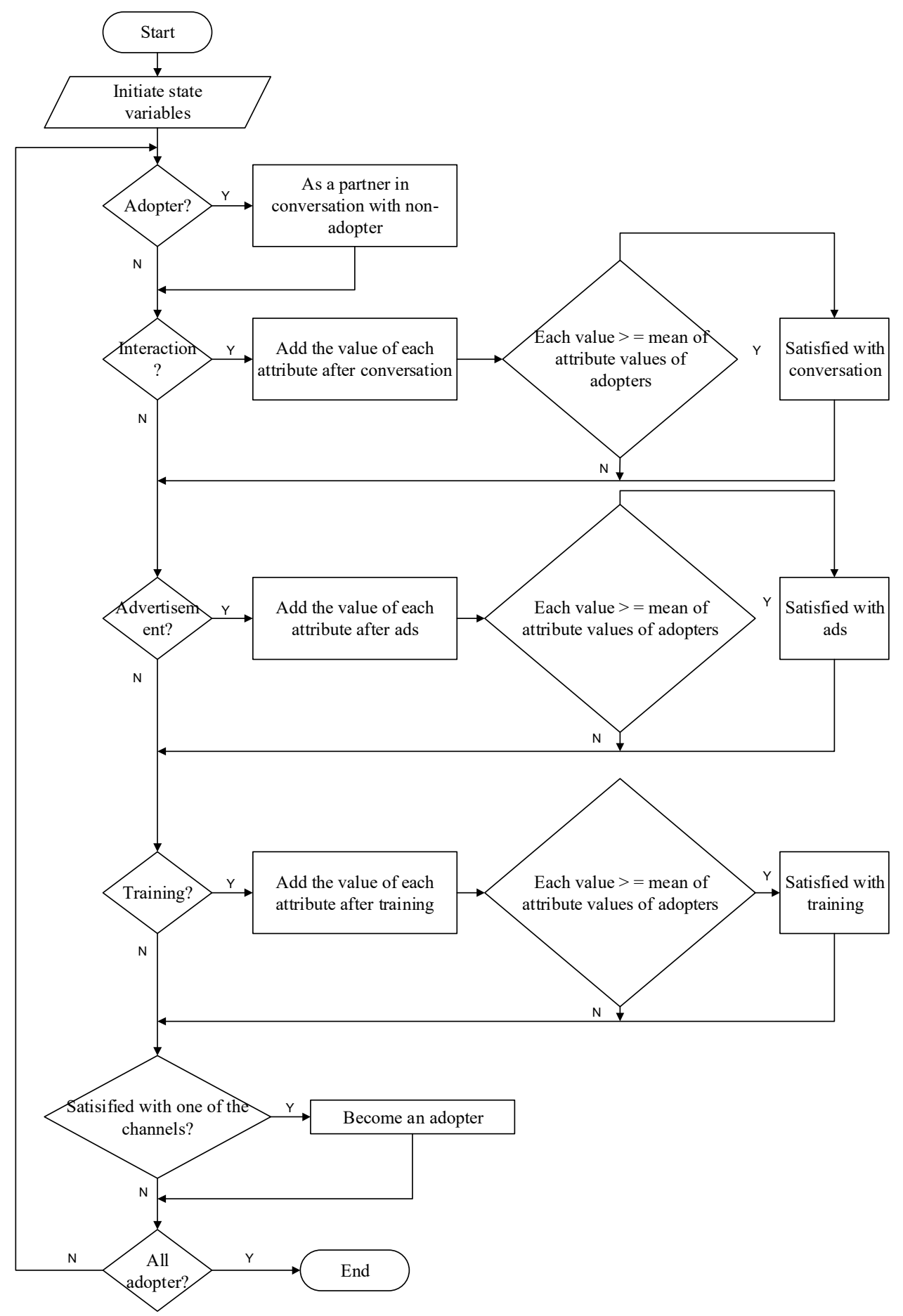

Fig. 1. Process overview.

Second channel in diffusing online marketplace is news from mass media. If an agent with a potential status receives information about an online marketplace from mass media or advertising, it will receive an additional value of the online marketplace and if this value is greater than the marketplace's online information adopter value of the ad, then the agent is satisfied with the advertisement and they may become new adopter or stay as nonadopter.

The third channel is facilitated training by government. If an agent with a potential status receives information about the online marketplace of the training, it will receive a value-added online marketplace information from the training and if the value is greater 
than the value of the online marketplace information adopter of the training, then the agent is satisfied with the training and they may become new adopter or stay as non-adopter.

\section{Next Agenda}

This paper presents a conceptual framework for the development of individual-based simulations (agent-based models) from the diffusion of the online marketplace. The conceptual framework includes defining agents / entities and developing process overviews. This paper describes UKM as an agent that has several attributes. The agent attributes include the current status of adoption and the factors that influence the adoption of an online marketplace by SMEs. The process overview explains how SME attributes shift the status of SMEs from non-adopters to adopters.

The conceptual framework will be used in this research. A questionnaire will be developed and distributed to trading SMEs. The results of data collection will be processed and elaborated to obtain any patterns of characteristics of SMEs in adopting the online marketplace.

The definitions of agents and their attributes and characteristic patterns of SMEs in adopting will be translated into agent-based simulation languages. To date, we have not determined the software for agent-based simulation programming. based on popularity, Netlogo is the strongest candidate to be chosen. Our simulation results will be analysed to gain a deeper understanding of the diffusion of online marketplace in the SME trading environment.

\section{References}

1. D. D. Utama, Darwanto, Pengembangan Usaha Mikro Kecil Dan Menengah (UMKM) Berbasis Ekonomi Kreatif Di Kota Semarang. http://eprints.undip.ac.id/40407/ (Diponegoro University Institutional Repository, 2013)

2. Internet World Stats, Internet Usage in Asia. https://www.internetworldstats.com/stats3.htm. (2017)

3. K. Ayuwuragil,. Kemenkop UKM: 3,79 Juta UMKM Sudah Go Online.https://www.cnnindonesia.com/ekonomi/20171115161037-78-

255819/kemenkop-ukm-379-juta-umkm-sudah-go-online. (CNN Indonesia, 2017)

4. E. M. Rogers, Diffusion of Innovations (5thed.). (The Free Press, NewYork, 2003)

5. R. MacGregor, L. Vrazalic, Electronic Commerce Adoption in Small to Medium Enterprises (SMEs) A Comparative Study of SMEs in Wollongong (Australia) and Karlstad (Sweden). https://www.uow.edu.au/content/groups/public/@web/@commerce/@econ/documents/ doc/uow012275.pdf. (2004)

6. R. Govindaraju, D. Chandra, IEEE $3^{\text {rd }}$ ICCSN, E-commerce adoption by Indonesian small, medium, and micro enterprises (SMMEs): Analysis of goals and barriers, 113$117(2011)$

7. S. Saptadi, I. Sudirman, T.M.A A. Samadhi, R. Govindaraju, Owner's Support, IT Sophistication and IT Adoption in Indonesian Manufacturing SMEs, (2015)

8. U. Wilensky, W. Rand, An Introduction to Agent-Based Modeling, (The MIT Press, London, 1955)

9. S.F. Railsback, V. Grimm, Individual-Based Modeling and Ecology, Princeton University Press, Princeton, 2005)

10. V. Grimm, U. Berger, D.L. DeAngelis, J.G. Polhill, J. Giskee, S.F. Railsback, EM, The ODD protocol: A review and first update, 221, 2760-2768 (2010) 